\title{
Uterine tumors resembling ovarian sex cord tumors: A case report and literature review
}

\author{
NILUFER CETINKAYA ${ }^{1}$, SEVDA BAS $^{1}$, ZELIHA FIRAT CUYLAN $^{1}$, \\ OZLEM ERDEM $^{2}$, SALIM ERKAYA $^{3}$ and TAYFUN GUNGOR ${ }^{4}$
}

\author{
${ }^{1}$ Department of Gynecologic Oncology, Zekai Tahir Burak Women's Health Education and Research Hospital, Ankara 06230; \\ ${ }^{2}$ Department of Pathology, Gazi University Medical Faculty, Ankara 06510; \\ ${ }^{3}$ Department of Obstetrics and Gynecology, Zekai Tahir Burak Women's Health Education and Research Hospital, \\ Ankara 06230; ${ }^{4}$ Department of Obstetrics and Gynecology, Hitit University Medical Faculty, Corum 19200, Turkey
}

Received January 5, 2015; Accepted November 16, 2015

DOI: $10.3892 / \mathrm{ol} .2016 .4076$

\begin{abstract}
Uterine tumors with ovarian sex cord-like elements are a rarely observed type of uterine body tumor with unknown etiology, and are divided into two groups: Endometrial stromal tumors with sex cord-like elements (ESTSCLEs) and uterine tumors resembling ovarian sex cord tumors (UTROSCTs). While ESTSCLEs are commonly associated with metastasis and recurrence, there is limited data in the relevant literature concerning the behavior of UTROSCTs. However, UTROSCTs are typically benign in nature. Although case numbers are limited, extra-uterine or lymph node metastasis has been reported. Surgical approaches may be altered according to the patient's age and desire for future fertility. Hysterectomies with bilateral salpingo-oopherectomy or hysteroscopic tumor resection are reported to be safe surgical treatment options. However, in the current report, a case of UTROSCT initially misdiagnosed as adenosarcoma following hysteroscopic tumor resection is presented. Staging surgery revealed the precise diagnosis of the tumor using appropriate immunohistochemical evaluations, and led to the discovery of a secondary tumor focus in the myometrium, adjacent to the location of the previously excised tumor. Thus, hysteroscopic
\end{abstract}

Correspondence to: Dr Nilufer Cetinkaya, Department of Gynecologic Oncology, Zekai Tahir Burak Women's Health Education and Research Hospital, Talatpasa Street, Ankara 06230, Turkey

E-mail: cetinkayanilufer@gmail.com

Abbreviations: ESTSCLE, endometrial stromal tumors with sex cord-like elements; UTROSCT, uterine tumors resembling ovarian sex cord tumors; IHC, immunohistochemical; CD, cluster of differentiation; CK, cytokeratin; SMA, smooth muscle actin; EMA, epithelial membrane antigen; ER, estrogen receptor; $\mathrm{PR}$, progesterone receptor

Key words: uterine tumors, sex cord-like elements, resembling ovarian sex-cord tumors resection is questionable as a definitive surgical treatment in patients exhibiting UTROSCT. If hysteroscopic resection is the selected treatment, close follow-up with diagnostic imaging is recommended.

\section{Introduction}

Uterine tumors resembling ovarian sex cord tumors (UTROSCTs) are a rare type of stromal tumor, initially reported in 1945 by Morehead and Bowman, which demonstrate sex cord-like differentiation (1-3). In a study performed by Clement and Scully (4), uterine tumors with sex cord-like elements were divided into two groups. Group I tumors exhibit a tumor histology similar to that of endometrial stromal tumors, with areas of sex cord-like structures comprising $10-40 \%$ of the total tumor mass. The tumors are associated with a risk of metastasis and recurrence, and are known as endometrial stromal tumors with sex cord-like elements (ESTSCLEs). By contrast, group II tumors are composed of $>50 \%$ sex cord-like cells, typically behave benignly and are known as UTROSCTs $(2,5,6)$. It has been determined that UTROSCTs exhibit polyphenotypic immunohistochemical (IHC) expression in the form of positivity for sex cord, epithelial and myeloid markers, and are classified as miscellaneous tumors of the uterine body (6).

The etiology of UTROSCTs remains unclear, and due to the rarity of such tumors, at present mortality rates are not known. To date, no specific diagnostic imaging features have been identified and thus, UTROSCTs are usually diagnosed by tissue biopsy (7). UTROSCTs are composed of epitheloid cells and nests of sex cord-like elements (6). Certain malignant neoplasms, including endometrial stromal sarcoma with sex cord elements, endometrioid carcinoma with sex cord-like features, adenosarcoma and carcinosarcoma may cause difficulties with regard to UTROSCT diagnosis, due to histopathological similarities (6). These tumors exhibit a low malignant potential (7), however, extrauterine or lymph node metastasis has been reported previously $(2,5,8)$. Hysterectomy with bilateral salpingo-oopherectomy or hysteroscopic tumor resection are considered safe treatment options, however, literature regarding disease management is limited (7). 
In the current study, a case of UTROSCT diagnosed in a hysterectomy specimen, which had previously been misdiagnosed as adenosarcoma following the hysteroscopic resection of a polypoid intrauterine mass, is presented. The aim of the present study was to highlight the difficulties of histopathological diagnosis of UTROSCT and investigate the safety of the hysteroscopic approach without performing hysterectomy. Written informed consent was obtained from the patient for publication of the present case report and accompanying image.

\section{Case report}

In August 2013, a 52-year-old woman (gravida 2, para 2) was admitted to Zekai Tahir Burak Women's Health and Education and Research Hospital (Ankara, Turkey) with the symptom of postmenopausal bleeding. The endometrial thickness was recorded at $11 \mathrm{~mm}$, and transvaginal ultrasonography revealed a $25 \times 14-\mathrm{mm}$ hypoechoic intrauterine mass, which was suspected of being a submucosal myoma. Laboratory evaluations were normal. Endometrial biopsy revealed proliferative endometrium, and the patient underwent a surgical hysteroscopy for myoma excision. Upon entry into the intrauterine cavity, an $\sim 15 \times 20$-mm solid mass, originating from the fundal area, was observed. The submucosal lesion was excised using a hysteroscopic resectoscope without any complications, and the tissue was sent for pathological examination. The permanent pathology report resulted in a diagnosis of adenosarcoma with hyperplastic glandular proliferation without atypia and sarcomatous differentiation, in the form of a low-grade endometrial stromal sarcoma with sex cord-like differentiation. The patient underwent staging surgery according to the International Federation of Gynecology and Obstetrics 2009 criteria for the staging of uterine sarcoma (9). Hysterectomy with a bilateral salpingo-oopherectomy and a pelvic and para-aortic lymph node dissection were performed.

In the permanent pathology, there was no marked definition of the residual tumor in the previously resected area due to cytolytic alterations of the tissue architecture. However, $0.6 \mathrm{~cm}$ beneath the neighboring endometrium there was an additional $0.8 \times 0.5-\mathrm{cm}$ tumor mass, which was suspected of being endometrial stromal sarcoma. Thus, paraffin-embedded tissue samples were reviewed by a gynecopathologist. Microscopic evaluation revealed that the tumor mass originating beneath the endometrial mucosa possessed cords and nests of epithelioid cells and a well-differentiated tubular structure, with sex cord differentiation and myometrial invasion (Fig. 1). IHC evaluation demonstrated positivity for cluster of differentiation (CD)99, calretinin, cytokeratin (CK)7, desmin, smooth muscle actin (SMA), estrogen (ER), progesterone (PR), vimentin and CD56. CK20 and epithelial membrane antigen (EMA) were negative; however, inhibin and $\mathrm{p} 53$ were sparsely positive, demonstrating a Ki-67 proliferation index of $<5 \%$. Based on the IHC results, a diagnosis of UTROSCT was reached. The patient received no post-operative adjuvant therapy and has remained under routine follow-up for 17 months with no evidence of progression.

\section{Discussion}

UTROSCTs belong to a group of miscellaneous neoplasms of the uterus with unknown etiology, based on the 2003 World

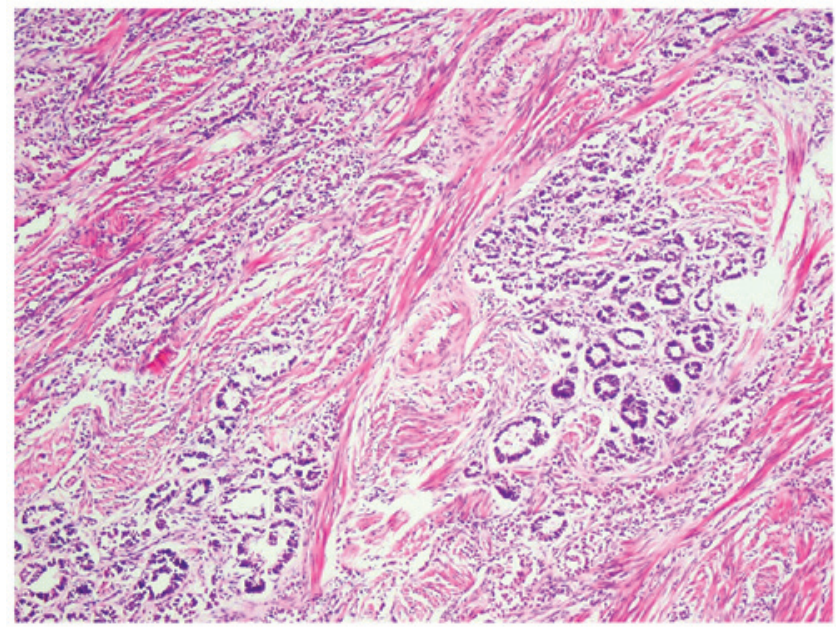

Figure 1. Representative image of the tumor mass, revealing cords and nests of epithelioid cells, and a well-differentiated tubular structure with sex-cord differentiation and myometrial invasion (hematoxylin and eosin staining; magnification, x100).

Health Organization classification (10). The tumors are known to be a disease of perimenopausal or postmenopausal women. Patients typically present with abnormal uterine bleeding. The exact diagnosis is confirmed via tissue biopsy due to the absence of specific diagnostic imaging. The tumor may be submucosal, subserosal or intramyometrially located. Generally, UTROSCTs exhibit expansive growth with or without tissue invasion. Histologically, the tumors are comprised of epithelioid cells and nests of sex cord-like elements (6). The diagnosis is typically reinforced by the results of polyphenotypic IHC expression in the form of positivity for sex cord (calretinin, CD99, inhibin, Wilms' tumor protein 1 and melanoma-associated antigen recognized by $\mathrm{T}$ cells), epithelial (pancytokeratin and EMA), myeloid (SMA, desmin and histone deacetylase 8) and a number of other markers (CD10, ER, PR, s100 and CD117) (6). Furthermore, the identification of two balanced chromosomal translocations, $t(X ; 6)$ (p22.3; 23.1$)$ and $\mathrm{t}(4 ; 18)(\mathrm{q} 21.1 ; \mathrm{q} 21.3)$, was reported in a case of UTROSCT in a study by Wang et al (11). Staats et al (12) indicated the presence of juxtaposed with another zinc finger protein 1-suppressor-of-zeste 12 protein gene fusion in a case of ESTSCLE, but not in cases of UTROSCT. Epithelioid leiomyoma, low-grade endometrial stromal sarcoma with sex cord elements, endometrioid carcinoma with sex cord-like features, adenosarcoma and carcinosarcoma are examples of tumors listed in the differential diagnoses (6). ESTSCLEs are differentiated from UTROSCTs due to their more aggressive nature and the possibility of metastasis and recurrence (6).

There is limited data in the relevant literature concerning the behavior of UTROSCTs. Although case numbers are limited, UTROSCTs tend to exhibit an indolent nature. However, there is relevant literature regarding the presence of extrauterine or lymph node metastasis $(2,5,8)$ and recurrence (13) in UTROSCTs. To date, hysterectomy has been used as the preferred method of surgical treatment for UTROSCTs, although a hysteroscopic resection of the tumor is performed in selected patients who express the desire to maintain their fertility, and this has been reported to achieve positive 
outcomes (14). However, as occurred in the present case, there may be accompanying tumor foci within the neighboring myometrium, and local excision procedures may therefore be insufficient to remove these, increasing the risk of recurrence or metastasis. To avoid these possibilities, a close follow-up is recommended in patients exhibiting UTROSCTs, due to unknown tumor characteristics. Affected patients, particularly those who are treated hysteroscopically, require additional attention in order to monitor the risk of tumor persistence or recurrence due to surgical insufficiency.

\section{Acknowledgements}

This case was presented as a poster presentation at the 15 th Biennial Meeting Of The International Gynecologic Cancer Society November 8-11, 2014 in Melbourne, Australia, and published in Int J Gynecol Cancer 24: 2014. The authors would like to thank Dr Anita L. Akkas (Bilkent University, Ankara, Turkery) for contributing to the English editing.

\section{References}

1. Morehead RP and Bowman MC: Heterologous mesodermal tumors of the uterus: Report of a neoplasm resembling a granulosa cell tumor. Am J Pathol 21: 53-61, 1945.

2. Mačák J, Dundr P, Dvořáčková J and Klát J: Uterine tumors resembling ovarian sex cord tumors (UTROSCT). Report of a case with lymph node metastasis. Cesk Patol 50: 46-49, 2014.

3. Abdullazade S, Kosemehmetoglu K, Adanir I, Kutluay L and Usubutun A: Uterine tumors resembling ovarian sex cord-stromal tumors: Synchronous uterine tumors resembling ovarian sex cord-stromal tumors and ovarian sex cord tumor. Ann Diagn Pathol 14: 432-437, 2010.
4. Clement PB and Scully RE: Uterine tumors resembling ovarian sex-cord tumors. A clinicopathologic analysis of fourteen cases. Am J Clin Pathol 66: 512-525, 1976.

5. Umeda S, Tateno M, Miyagi E, Sakurai K, Tanaka R, Tateishi Y, Tokinaga A, Ohashi K and Furuya M: Uterine tumors resembling ovarian sex cord tumors (UTROSCT) with metastasis: Clinicopathological study of two cases. Int J Clin Exp Pathol 7: 1051-1059, 2014.

6. Pradhan D and Mohanty SK: Uterine tumors resembling ovarian sex cord tumors. Arch Pathol Lab Med 137: 1832-1836, 2013.

7. Liu CY, Shen Y, Zhao JG and Qu PP: Clinical experience of uterine tumors resembling ovarian sex cord tumors: A clinicopathological analysis of 6 cases. Int J Clin Exp Pathol 8: 4158-4164, 2015.

8. Biermann K, Heukamp LC, Büttner R and Zhou H: Uterine tumor resembling an ovarian sex cord tumor associated with metastasis. Int J Gynecol Pathol 27: 58-60, 2008.

9. Zalewski K, Doniec J, Baranowski W and Bidziński M: Revised FIGO staging systems for gynecologic malignancies - 2009 update. Ginekol Pol 81: 778-782, 2010 (In Polish).

10. Silverberg SG, Kurman RJ, Nogales F, Mutter GL, Kubik-Huch RA and Tavassoli FA: Tumours of uterine corpus. In: Pathology and Genetics of Tumours of the Breast and Female Genital Organs. Tavassoli FA and Devilee P (eds). 3rd edition. IARC Press, Lyon, pp217-257, 2003.

11. Wang J, Blakey GL, Zhang L, Bane B, Torbenson M and Li S: Uterine tumor resembling ovarian sex cord tumor: Report of a case with $\mathrm{t}(\mathrm{X} ; 6)(\mathrm{p} 22.3 ; \mathrm{q} 23.1)$ and $\mathrm{t}(4 ; 18)(\mathrm{q} 21.1 ; \mathrm{q} 21.3)$. Diagn Mol Pathol 12: 174-180, 2003.

12. Staats PN, Garcia JJ, Dias-Santagata DC, Kuhlmann G, Stubbs H, McCluggage WG, De Nictolis M, Kommoss F, Soslow RA, Iafrate AJ and Oliva E: Uterine tumors resembling ovarian sex cord tumors (UTROSCT) lack the JAZF1-JJAZ1 translocation frequently seen in endometrial stromal tumors. Am J Surg Pathol 33: 1206-1212, 2009.

13. O'Meara AC, Giger OT, Kurrer M and Schaer G: Case report: Recurrence of a uterine tumor resembling ovarian sex-cord tumor. Gynecol Oncol 114: 140-142, 2009.

14. Anastasakis E, Magos AL, Mould T and Economides DL: Uterine tumor resembling ovarian sex cord tumors treated by hysteroscopy. Int J Gynaecol Obstet 101: 194-195, 2008. 